
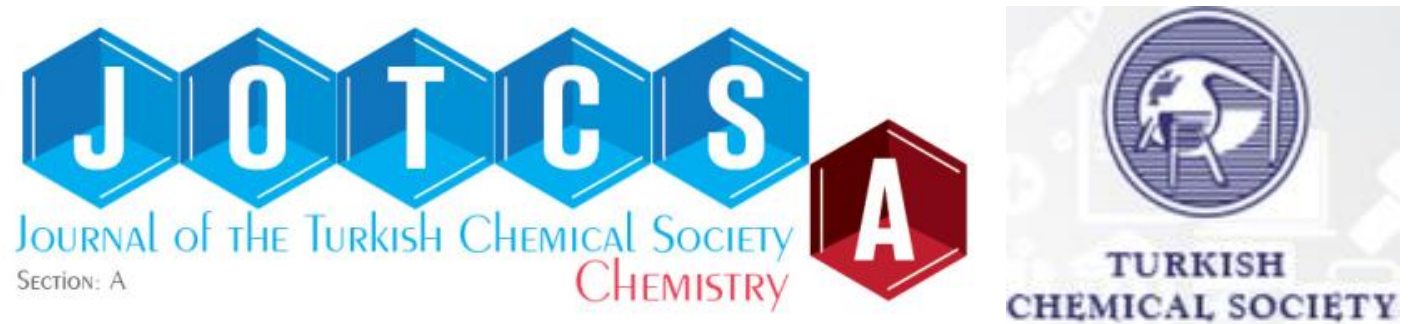

\title{
VALIDATION OF MOHR'S TITRATION METHOD TO DETERMINE SALT IN OLIVE AND OLIVE BRINE
}

\author{
Mürüvvet SEZEY $\square$ and Perihan ADUN* $\square$ \\ Department of Food Engineering, Faculty of Engineering, Near East University, 99138 Nicosia-Mersin 10 TRNC, \\ TURKEY.
}

Abstract: The aim of this study was to test Mohr method's performance characteristics and to check acceptability of test results during the routine salt analysis in the production phase of Çakıstes table olives. The method was validated using three fortified samples, i.e. salt solutions in water, cracked olive's brine and olive at three different levels of 3,5 and $7 \%$ salt concentration at three different times. Overall recovery of the method was $107 \%$ for all three commodities over the validation range with a relative standard deviation of $5 \%$ $(n=162)$. The regression coefficient $\left(R^{2}\right)$ was found to be 0.998 in olive matrix. Typical limit of detection was $0.1 \%$ with the method.

Keywords: Method validation, salt analysis, Mohr method, olive, brine.

Submitted: December 13, 2018. Accepted: July 17, 2019.

Cite this: Sezey M, Adun P. VALIDATION OF MOHR'S TITRATION METHOD TO DETERMINE SALT IN OLIVE AND OLIVE BRINE. JOTCSA. 2019;6(3):329-34.

DOI: https://doi.org/10.18596/jotcsa.496563.

*Corresponding author. E-mail: perihan.adun@neu.edu.tr.

\section{INTRODUCTION}

Method validation is the series of procedures used to demonstrate that the analytical method utilized for a specific test is suitable for its intended purpose. Results from method validation can be used to evaluate the reliability and precision of that method and it is an integral part of good laboratory practices (1).

Method validation should be applied according to ISO 17025 (2), when a method is developed inhouse or obtained from the literature/third parties. Whenever a laboratory undertakes method modification or there is a change in the performance of the method over time, the effects of analytical variables should be established.

Different method performance parameters will be important in different situations. Trueness has at most importance for calculating absolute values of properties or analytes. It should be noted that the term 'accuracy' is often used in documents/standards referring to method validation. Under current ISO definitions, accuracy could be defined as the agreement between a measurand a true value, actually it includes the effect of both precision and trueness, since a measurand is an average of individual test results and dispersion of test results effects trueness and bias. Precision, which is closeness of test results to each other, is another important method performance criterion for all measurements but particularly in comparative studies. Method must be tested to assess sensitivity, linearity, working range and limit of detection (LOD). Sensitivity is defined as the slope of the calibration curve. Detection limit is the lowest detectable level of analyte distinguishable from zero. The higher the analytical sensitivity is, the lower the detection limit will be (3).

A test laboratory shall have a procedure for the determination of measurement uncertainty and 
shall apply to this procedure. Uncertainty does not assure trueness; however in an analytical point of view, uncertainty defines the range of the values that could reasonably be attributed to an analytical result. Uncertainty arises not only from random errors in the analysis such as short-term deviations in temperature, relative humidity and power source variations, but also from systematic errors such as wrong solvent use, changes in instrumental calibrations. When laboratories report uncertainty together with an analytical result, it gives a quantitative indication of the quality of the analytical result and allows the user to make decision. The confidence can be placed on a result when it is compared with certain limits defined in a specification or regulation. The validation of the result and to compare analytical results from different laboratories can be possible by using uncertainty value (4). Different approaches can be used to estimate measurement uncertainty such as Gum Approach, method validation and use of method performance data, inter-laboratory studies, internal quality control studies and external quality assessment data (5).

Çakıstes is one of the most typical table olive products of Northern Cyprus prepared by cracking pink or green domestic olives. Domat, Memecik and Yamalak varieties are used to prepare Çakıstes. After the olives are transported to the plant, they are graded and scratched on 2 or 3 sides and put into fresh water to remove bitter taste. The water should be changed every day to obtain the desired taste. Then, olives are transferred into brine which is composed of $7 \% \mathrm{NaCl}, 1 \%$ citric acid and $1 \%$ $\mathrm{CaCl}_{2}$, in fermentation tanks. The brine salt ratio is increased progressively keeping salt ratio constant at $7-8 \%$. When salt ratio in olives reaches to $5-6 \%$, Çakıstes olives are now ready for consumption and packaging. This process takes almost one month (6).

Sodium chloride $(\mathrm{NaCl})$ concentration is a crucial parameter which strongly influences the storage and quality of table olives. Its level is very effective to achieve stability of the products, as salt prevents growth of pathogens and hence its spoilage. In recent years, consumers have developed a tendency to low sodium intake, since a diet rich in sodium leads to higher blood pressure. Therefore, scientists have focused on the viability, application and consequences of replacement of sodium with calcium or potassium in table olive fermentation (7).

Selection of a method to determine sodium chloride content of any food is an important criterion designing a quality assurance plan. There are various methods available for determining salt content of food; every single method has their own advantages and limitations. Based on method performance criteria, analysts prefer standard methods to determine salt content such as refractometry, ion-selective electrodes, and titration (8). Mohr's titration method was applied and validated in this study, since this method is widely used for salt analysis in olive, olive brine and many other food samples.

The Mohr's method, named after Karl Friedrich Mohr, determines the chloride ion concentration of a solution by titration with silver nitrate. As the silver nitrate solution is slowly added, a precipitate of silver chloride forms. The end point of the titration occurs when all the chloride ions are precipitated. Then additional silver ions react with the chromate ions of the indicator, potassium chromate, to form a red-brown precipitate of silver chromate (9):

$$
\begin{aligned}
& \mathrm{Ag}_{(\mathrm{aq})}+\mathrm{Cl}_{(\mathrm{aq})} \rightarrow \mathrm{AgCl}_{(\mathrm{s})} \quad\left(\mathrm{K}_{\mathrm{sp}}=1.6 \times 10^{-10}\right) \\
& 2 \mathrm{Ag}^{+}{ }_{(\mathrm{aq})}+\mathrm{CrO}_{4}{ }^{2-}{ }_{(\mathrm{aq})} \rightarrow \mathrm{Ag}_{2} \mathrm{CrO}_{4}(\mathrm{~s})\left(\mathrm{K}_{\mathrm{sp}}=1.1 \times 10^{-12}\right)
\end{aligned}
$$

The aim of this study is to validate Mohr's method to determine the amount of salt in olive and olive brine and to evaluate accuracy and precision of the method and to estimate measurement uncertainty. Acceptability of test results was also checked during the Çakıstes production season by an internal quality control technique based on comparisons of duplicated test results.

\section{EXPERIMENTAL}

Water, olive brine and olive samples fortified with $\mathrm{NaCl}$ at three different levels i.e. 3, 5 and $7 \%$ were used as material for validation experiments.

\section{Preparation of fortified water samples}

Distilled water enough for the experiments was fortified with pure sodium chloride $(\mathrm{NaCl})$ at 3 different levels i.e, 3, 5 and $7 \%$, for 6 replicates at each level and at three different occasions.

\section{Preparation of fortified olive brine}

Olives were manually picked from trees. They were at green color maturity period. Samples were taken in plastic boxes and transferred to factory. Firstly, olives were washed in washing machine and separated according to size in sorting machine. Then they were cracked with crushing machine and put into pure water as same as in practice. Olives were kept in water for 3 days to include olive matrix components into brine water representing the conditions in practice. Olives were then separated from water and this water was fortified with pure sodium chloride $(\mathrm{NaCl})$ at 3 different levels i.e., 3, 5 and $7 \%$, enough for 6 replicates at each level and for three different occasions. 


\section{Preparation of fortified olive matrix}

$2 \mathrm{~kg}$ of olive were picked from trees. They were transferred to the laboratory. Olives were washed and fruit flesh were chopped, then comminuted and homogenized. Homogenized olive samples were fortified with pure sodium chloride $(\mathrm{NaCl})$ at 3 different levels, i.e, 3, 5 and $7 \%$, for 6 replicates at each level and for three different occasions. Fortified samples were kept for one day at room temperature, so that $\mathrm{NaCl}$ can incorporate with olive matrix. Next day, salty olive samples were filtered through filter cloth.

\section{Preparation of internal quality control test samples}

Picked olives were washed in washing machine and sorted. Then, they were cracked with crushing machine and put in polyester boxes. When the box was full with olives, brine, which contained $7 \%$ salt and $1 \%$ citric acid was added. During fermentation period of olives, brine samples were taken from selected boxes in duplicates and analyzed in different days. Total 18 analyses were performed and the following formula was used to calculate laboratory uncertainty from differences of duplicate measurements of test samples.

$$
s=\frac{1}{\sqrt{2}} \sqrt{\frac{\sum d^{2}}{n}}=\sqrt{\frac{\sum d^{2}}{2 n}}
$$

Where s: standard deviation of analysis from duplicate laboratory determinations

$\mathrm{d}$ : the difference of duplicates in one laboratory

$\mathrm{n}$ : the number of data pairs

\section{Preparation of calibration curve}

Calibration curve was constructed to assess limit of detection, although calibration curve is not used for quantitation of $\mathrm{NaCl}$ amount in routine analysis. Olives were picked from trees and then transferred to the laboratory. They were washed and fruit flesh were chopped, then comminuted and homogenized. Homogenized olive samples were fortified with pure sodium chloride $(\mathrm{NaCl})$ at 7 different levels, i.e, 1, 2, 3, 4, 5, 6 and 7\%. Fortified samples were kept for one day, so that $\mathrm{NaCl}$ can incorporate with olive matrix. Next day, salty olive samples were filtered through filter cloth and then used for the construction of calibration curve with replicate titrations.

Salt analysis by using Mohr's titration method All fortified samples and olive brine samples taken during the olive fermentation period for internal quality control purpose were analyzed for the salt content by Mohr titration method by 6 replicates at the level of 3, 5 and $7 \%$ salt and at three different occasions.

Procedure is described below:

- An aliquot of $1 \mathrm{~mL}$ was taken from brine and put into an Erlenmeyer flask.

- $0.5 \mathrm{~mL}$ of $5 \%$ potassium chromate (indicator) was added.

- The burette was filled with $0.1 \mathrm{~N}$ of $\mathrm{AgNO}_{3}$ until the zero point.

- The sample was titrated with standardized $\mathrm{AgNO}_{3}$ solution until the first perceptible pale red-brown color.

- The color should remain constant for 30 seconds.

- Titration volume was recorded.

- The following formula was used to calculate the amount of salt.

$$
N a C l \text { content }(\%)=\frac{V \times N \times F \times 0.0585 \times 100}{m}
$$

V: Consumption of $0,1 \mathrm{~N} \mathrm{AgNO}_{3}$ in titration

$$
\begin{aligned}
& \mathrm{N}: \text { Normality of } \mathrm{AgNO}_{3} \\
& \mathrm{~F}: \text { Factor of } 0,1 \mathrm{~N} \mathrm{AgNO}_{3} \\
& \mathrm{~m}: \text { mass of sample }(\mathrm{g})
\end{aligned}
$$

\section{RESULTS and DISCUSSION}

\section{Validation results of fortified matrices}

Table 1 shows the recoveries and repeatability values for all fortified matrices at each occasion of analysis. Salt recoveries from fortified pure water changed between $101 \%$ and $121 \%$, from brine $94 \%$ to $117 \%$ and from olive solutions $100 \%$ to $119 \%$. Repeatability values changed from $3 \%$ to $6 \%$ RSD among the replicates of three different fortification levels at the same day. 
Sezey M, Adun P. JOTCSA. 2019; 6(3): 329-334.

Table 1. Method validation characteristics for different matrices $(n=162)$.

\begin{tabular}{lccc}
\hline Matrix & Days of Analysis & $\begin{array}{c}\text { Average Recovery } \\
(\mathbf{( \% )}\end{array}$ & $\begin{array}{c}\text { Precision } \\
\text { as Repeatability of Recoveries } \\
\text { (RSD\%, } \mathbf{n = 1 8} \text { ) }\end{array}$ \\
\hline Water & 1 & 109 & 4 \\
& 2 & 110 & 4 \\
\hline Olive brine & 3 & 113 & 5 \\
& 1 & 103 & 3 \\
& 2 & 105 & 3 \\
Olive & 107 & 5 \\
& 1 & 107 & 6 \\
& 2 & 106 & 4 \\
\hline
\end{tabular}

\section{Accuracy and reproducibility of the Mohr's Method}

Table 2 summarizes the recoveries for all fortified matrices at each fortification level. Mean recoveries for olive brine and olives were found as $105 \%$ and $106 \%$ respectively, whereas $111 \%$ for direct aqueous solutions with the relative standard deviations of 4,4 and $5 \%$ respectively (see Figure 1). Our findings are in accordance with the similar titrimetric method validation criteria, although not any validation data on Mohr's method could be found.

Finally, overall recovery, in other words, accuracy of the Mohr's titration method was $107 \%$ with RSD of $5 \%(n=162)$ for three matrices, three levels and three different occasions.

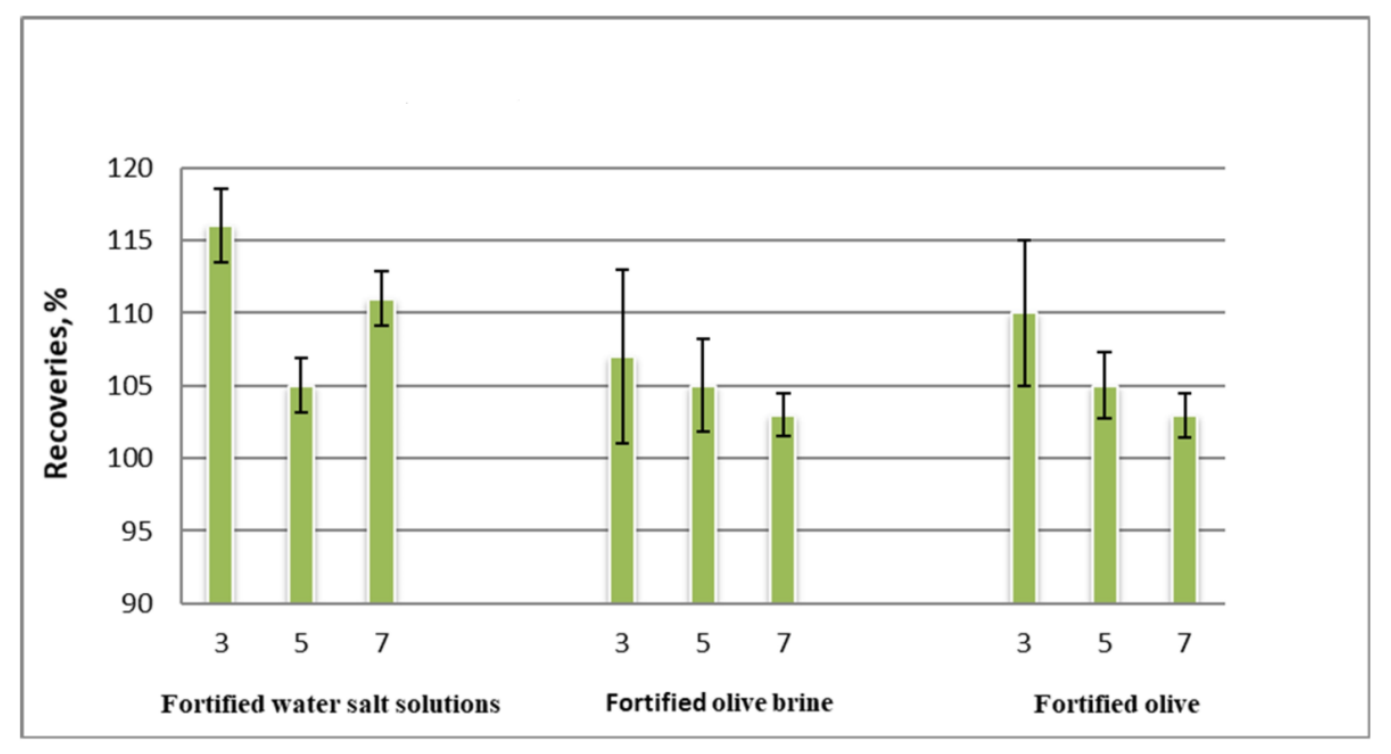

Figure 1. Mean recoveries and RSD values of fortified water solutions, fortified olive brine and fortified olive at three different salt level (\%).

Table 2. Method validation characteristics of the method at different levels independent of the matrix. Analysis uncertainty is expressed as $\mathrm{CV}_{\mathrm{A}}(\mathrm{n}=162)$.

\begin{tabular}{ccc}
\hline Fortification Level & $\begin{array}{c}\text { Accuracy } \\
\text { (Average Recovery, \%) }\end{array}$ & $\begin{array}{c}\text { Precision } \\
\text { as Reproducibility of Recoveries } \\
\text { (RSD\%, } \mathbf{n = 1 8 )}\end{array}$ \\
\hline $3 \%$ & 111 & 6 \\
\hline $5 \%$ & 105 & 2 \\
\hline $7 \%$ & 106 & 4 \\
\hline Overall recovery & $\mathbf{1 0 7}$ & $\mathbf{5 *}$ \\
\hline
\end{tabular}

*coefficient of variation $\left(\mathrm{CV}_{\mathrm{A}}\right)$ for the analysis.

Internal Quality Check Results Obtained from Duplicate Analysis of Olive Brine
Olive brine samples were taken during the fermentation period for the estimation of laboratory 
uncertainty, three sampling parties were selected during one-month period. Three samples were taken from each barrel with weekly intervals. Sample 1 was analyzed on the day of sampling, the 2nd sample was analyzed the next day and sample
3 was stored as a control sample. Total 18 samples were analyzed in the same manner and laboratory uncertainty was calculated as $3 \%$ (Table 3 ), which was better and in accordance with analysis uncertainty (5\%).

Table 3. Results of two groups of measurements under repeatability conditions for the estimation of laboratory

\section{Linearity and Limit of Detection (LOD)}

Linearity and limit of detection are important method performance criteria to be determined in method validation experiments. One simple way to estimate linearity and LOD is the use of calibration curves in matrix (10). The standard deviations of relative residuals (Srr), which is a decisive parameter in internal quality control of linearity, should be $\leq 0.1(11-12)$. This was the case in the study that correlation coefficient $\mathrm{R}^{2}$ was 0.998 and Srr was 0.03 (Figure 2). Typical LOD value for salt calculated from the calibration curve was found to be $0.1 \%$.

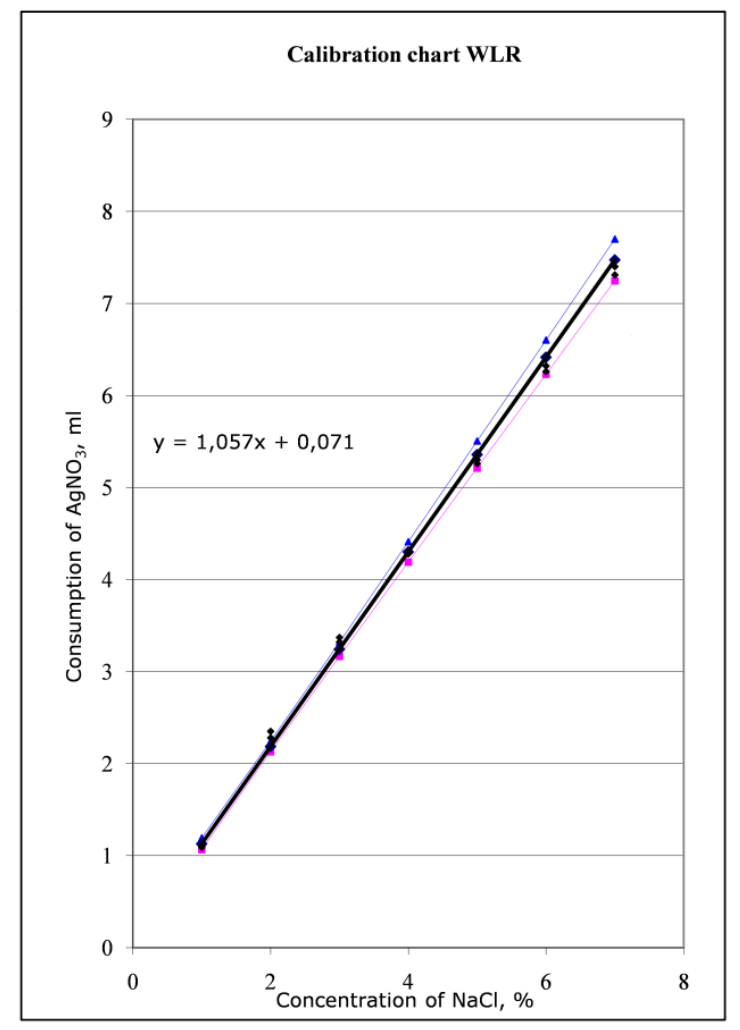

Figure 2. Calibration graph of salt analysis by using Mohr method. 


\section{CONCLUSION}

Mohr's titration method for the determination of salt amount in olive and/or olive brine was successfully validated, since the accuracy and precision of the method were within the acceptable ranges (accuracy $70-120 \%$ and RSD 5\%). Laboratory uncertainty value was in accordance with method's reproducibility value $\left(\mathrm{CV}_{\mathrm{A}}\right)$ from validation study. Mohr's method can be used for routine analysis of salt determination by implementing quality control measures during its use.

This study was presented as an oral presentation at the Thirtieth National Chemistry Congress, 5-8 November 2018, Famagusta, Cyprus.

\section{REFERENCES}

1. Huber, L. Validation of Analytical Methods and Procedures. Validation and qualification in Analytical Laboratories. 2007; 125.

2. Karaman, D., Akalın, A.S. Süt teknolojisinde metot validasyonu ve uygulamaları. Türkiye 10. Gıda Kongresi. 2008; 749-51.

3. Method Validation Course 1125 (c) 2015 LGC Limited

4. EURACHEM/CITAC Guide. Quantifying Uncertainty in Analytical Measurement. Second Edition. 2000.

5. Türk Akreditasyon Kurumu (TURKAK). R20.02, Deney/Analiz Sonuçlarındaki ölçüm belirsizliği tahmini için TURKAK Prensipleri. 09.07.2015.
6. "Present and Future of the Mediterranean Olive Sector". Zaragoza (Spain). 26-28 November 2012.

7. Romeo, F.V. Microbiological aspects of table olives. The microbiological hazards in table olives. 2012.

8. Masulli, D. Determining salt in food. 2015; Retrieved from: www.foodqualityandsafety.com/.../deter mining-salt-in-food

9. Yoder, L. "Adaptation of the Mohr Volumetric Method to General Determinations of Chlorine". Industrial \& Engineering Chemistry. 1919; 11 (8): 755.

10. Aysal, P., Ambrus, A., Lehotay, S.J., Cannavan, A. Validation of an efficient method for the determination of pesticide residues in fruits and vegetables using ethyl acetate for extraction. Journal of Environmental Science and Health Part B. 2007; 42 (5): $481-90$.

11. Gozek, K.; Yucel, U.; Ilim, M.; CayciAysal, P. \& Tuncbilek, A.S. C14dimethoate residues in olive oil during oil processing. Isotope Aided Studies of Pesticide Residues during Food Processing. 1995; 33-40.

12. Miller, J.N., Ambrus, A. Statistics in calibration analysis. Manual on Basic Statistics. FAO/ IAEA Training and Reference Centre for Food and Environmental Protection Section. 2000; 1-18. 